\title{
The Articulations of the In-between Realm in Sardinia
}

\author{
Francesca Oggiano \\ DICAAR (Dipartimento di Ingegneria Civile, Ambientale e Architettura), Cagliari 09123, Italy
}

\begin{abstract}
At the base of the reflection developed in this research work, there is the concept of habitat as a system, as an articulated "whole" that cannot be explained with the simple sum of its parts. The concept of habitat, in fact, implies issues of dialectic spaces, in other words, those settings that can be defined as relational subsystems within the urban/domestic scale. This essay has its roots in the CIAM (Congrès International d'Architecture Moderne (in English: International Congress of Modern Architecture)) of 1953, during which the complementarity of the outside space next to the dwelling and its relevance within the project discipline, have been affirmed. In particular, assimilating the lesson of Aldo van Eyck, this work investigates the deepest issues of the concept of threshold. The analysis makes use of the work-tools of critical reading and comparison between urban and rural habitats, with different density levels, whose relational fabrics have been layering over time permeable "thicknesses" which articulate complex threshold spatial configurations.
\end{abstract}

Key words: Habitat, threshold, doorstep, in-between realm, Aldo van Eyck.

\section{Introduction}

The intellectual corpus of the architects of the second generation of the modern period, with particular reference to the members of Team 10, defined-since the CIAM (Congrès International d'Architecture Moderne (in English: International Congress of Modern Architecture)) in the 1953-the concept of habitat as a system, as a whole that cannot be explained by the simple sum of the parts that compose it. ${ }^{1}$

The unicum nature of the urban organism is clearly evident in the complex articulation of its parts, in the relations of contiguity and measured proximity that are structured between the elements of the private,

Corresponding author: Francesca Oggiano, Ph.D., engineer and architect, research field: habitat project, with particular focus on the in-between places.

${ }^{1}$ Montaner, M. J., Sistemas Arquitectònicos Contemporaneous. pg. 11-12, "I believe, therefore, that a system is a set of heterogeneous elements (materials and otherwise), of different scales, which are related to each other according to an internal organization through which the matching of the complexity of the context follows strategically and which constitutes a whole that cannot be explained by the mere sum of its parts. Each part of the system exists as a function of another; There are no isolated elements" [1]. public and semi-public sphere. ${ }^{2}$

The habitat implies the issues of dialectical spaces, which are legible at the intermediate scale of relations and defined as sub-systems of the urban/domestic scale.

The program termed of CIAM '53, "Extensions of the Dwelling"3 affirms precisely the complementarity of the outside space adjoining the dwelling and

\footnotetext{
${ }^{2}$ Aldo van Eyck, "Steps towards a Configurative Discipline." Article published in Forum, August 1962, pg. 328. "(...) When I say, therefore, make a welcome of each door and a countenance of each window: make of each a place, because man's home-realm is the in-between realm-the realm architecture sets out to articulate, the intention is again to unmask false meaning and to load the meaning of size with what right-size implies! As soon as the equilibrating impact of the in-between real-extended so that it coincides with the bunch of places both dwelling and city should be-manifests itself in a comprehensibly articulated configuration, the chances that the terrifying polarities that hitherto harass man's right composure may still be reconciled, will certainly be greater".

${ }^{3}$ Eric Mumford, The CIAM Discourse on Urbanism, 1928-1960. foreword by Kenneth Frampton, pg. 226. “(...) The work program for CIAM 9 prepared by Wogenscki after the Sigtuna discussions and issued to members in January 1953 stated that "CIAM 9 will not resume the study of ... (the) four functions but will concentrate upon LIVING and everything that man plans and constructs for living". The program emphasized that there was no intention of limiting the subject to the family dwelling, but instead the work should address "such things in the immediate environment as are necessary for a complete life". These the program termed "Extensions of the Dwelling", reflecting Le Corbusier's idea of "lodgement prolongé" [2].
} 
confirms its relevance within the framework of the project, by introducing the radical and new concept of the doorstep [3].

In this way, the theme of urban design is specified as the definition of relations between things. The empty space is the living space, the matter of the project. The empty space is the open space, the invisible substance between buildings which allows to articulate complexities. The disaggregation of the object is opposed to the idea of assimilation of the object within the system, it is conceived as part of the whole, including a matrix that starting from the existing elements assimilates what is already there in a complex and unified configuration according to reciprocity and context relations.

The habitat is, therefore, recognized as a holistic structure that is generated through the combination of the various elements within a system according to specific mechanisms, relational subsystems and minute textures of open and empty spaces that generate a micro-regulated and diversified urban solid. It is possible to define the settlement as a living machine, revising its modern meaning and referring to the ability of the fabric to aggregate elements, overcoming the object scale in order to reach the complexity of the whole, entirely organized and functioning at different scales.

The fine-grained urban systems, minutely configured, are able to structure the small scale. Small size spaces are articulated and woven within the habitat fabric. The urban spaces of the intermediate dimension can be recognized in those spatial devices: alleys, widenings, thresholds, vestibules, interstices and common courts that are capable of affirming the scale variation and that perform the role of gradients in articulating the relation between urban space and domestic proximity.

The "texture" of the habitat, extending the fabric metaphor to those portions of the settlement which are regulated by small-size spaces, produces a spatiality that governs the intermediate scale and is able to stitch spaces with different nature and character, vestibules and gradients that introduce to the intimate places of alleys and common courts; connectors with a compressed section which are sufficient to affirm variations and build a "long time" walk-through.

The habitat, articulation of urban facts and evolving human phenomena with a profound connection between them, is a system of places that constantly re-defines itself achieving adequacy to time and community. The habitat is, therefore, a process by virtue of its essence of adaptability, for its being a combination of complexities constantly in relation with time and individuals. The built environment assimilates the settlement pressures and mutations of the ways of living and provides possible forms of adaptation by resetting the textured fabric which structures the urban system.

In particular, the lesson of Aldo van Eyck, provides an investigation on the deepest issues of the concept of doorstep. The young architect from Team 10, at the end of $50 \mathrm{~s},{ }^{4}$ provided an erudite reinterpretation of the spatiality of the fabrics with Arab matrix, assimilating the complexity of spatial bonds, of the relational micro-structures at the intermediate scale that are typical of the systemic organism of the casbah. The system-casbah clarifies the lack of interest in a clear, immediately-legible, rational and simple condition, in favor of an intellectual interest to grasp the richness and density of meanings that the habitat possesses.

The words of Aldo van Eyck express the striving for a new concept of space that has the strength to change the paradigms of the habitat project, the description of which is defined in abstract terms, negations, bringing out the indeterminacy as a prevailing character and the tension as outcome. A space made of tensions, could be summed up, it is the meeting place of the "twin phenomena":

- the inside and the outside;

${ }^{4}$ Vers une "casbah" organisée (in English: towards a "ordered casbah"), in the architectural magazine forum $7 / 1959$, last page. 
- the public and private spheres;

- the stasis and dynamism.

The notion of "entre-deux", in-between, breaks the false alternatives of the meeting and merging of the extremes, it is actually about conceiving a "third" whose conception refers neither to the one nor to the other, nor to an intermediate dimension between the two, but to the resulting tension. ${ }^{5}$

Within the relational systems of the habitat-the fabrics and textures - doorsteps stand out as spaces of formal relationship, mediating spaces between the dwelling and the street, whose indefinite limits constitute the third element that stands between the individual and the collective sphere, between the inside and the outside. This is where the complexity of the spatial structure of the habitat emerges, in the abandonment of the elementary scheme that divides the private from public, in favor of a structure of micro-environments, measured spaces that accompany the transition, that blend the individual dimension into the collective one while keeping intact the identities of the two spheres, the nature of the two entities.

The fabric, fine-grained settlement metaphor, describes furthermore the minute scale in which the habitat texture articulates spaces and uses.

\footnotetext{
${ }^{5}$ Secci, C., and Thibault, E. 2005. "Espace Intermédiaire. Formation de Cette Notion chez les Architectes." In La Société des Voisins, edited by Haumont, B., and Morel, A. pg. 23-35. In particular refer to the paragraph: "The emergence of a reflection on the intermediate space in the post-war CIAM" where the theoretical path concerning the definition of the threshold space of Aldo van Eyck is explained: "He (van Eyck) considers the threshold on a metaphorical level as a place that creates tension between different oppositions. This sense, among others, complies with the reflection of the philosopher Martin Buber. Van Eyck talks about "the greater reality of the threshold" in reference to what Buber called Gestalt gewordene zwischen, which we can try to translate as "the in between acquiring a tangible form". For the notion of in between, Buber offers a critique aimed at the "breaking of false alternatives": One cannot choose between individualism and collectivism. One has to find a "third choice" whose conception refers not to one or the other, nor to any mediation between the two, but rather the resulting tension. Van Eyck constructs his argument on the reconciliation of opposites, the "twin phenomena" which are the individual and the collective, but also unity-diversity, inside-outside, motion-rest, dynamic-constant, centrality-distribution... These opposites allow an interpretation and rewriting of this reflection in terms of space and time. (Strauven [1994] 1998)" [4].
}

The controlled reading of reality reveals the adequacy of the living spaces, which is intrinsic in the size of the space relations, in the ability of the urban space-legible as a fluid - to extend itself and to be modulated at different scales in street, square, widening, alley and finally doorstep.

These issues concern architectural aspects since the space of living poses questions about measure, size, scale, proportion, proximity and section. The character, atmosphere, the "emotional component", 6 the use and appropriation of space are consequential and related to spatial structure, to its links and interrelationships with the built surroundings, to the mutual relationship of each part with the system to which it belongs and from which it is generated. Therefore, it is no more possible to talk about object, simple container, without incurring the sense depletion of the space of the habitat, without sacrificing the relational and collective component of living and reside in a place.

\section{The Doorstep as Area of Penetration and Relation}

Doorsteps are the spaces of relativity, small spaces that exist by virtue of their dependency on the system; They are mediation spaces, which are in the middle between parts regulating their ratio and dialectic. They do not identify themselves with the entities that put in relation, they are the "other" that defines their relationship. Their dimension of "in-between" makes them places of multiplicity and of living, dense of use meanings and of relation possibilities due to the vocational indefiniteness which characterizes them. They are small-scale indeterminate spaces, where the effect of the size, ${ }^{7}$ which Aldo van Eyck talks about, is clearly shown.

\footnotetext{
${ }^{6}$ Aparicio Guisado, J. M. El muro. 2006. "Concepto Esencial en el Proyecto Arquitectónico: La Materialización de la Idea y la Idealización de la Materia." pg. 17, Biblioteca nueva.

${ }^{7}$ Aldo van Eyck, "Step towards a Configurative Discipline." Article published in Forum, August 1962, pg. 327. “(...) What has right-size is at the same time both large and small, few and many, near and far, simple and complex, open and closed; will furthermore always be both part and whole and embrace both unity and diversity".
} 
They are spaces of measured passage, of meaning transit, mediation volumes that become place, become spaces that open up "living" possibilities, which build a spatial experience in the act of crossing them. One can talk about doorstep space when space, besides being intermediate and indeterminate, has "measured" spatial characters, is small, sometimes compressed and therefore capable of wrapping the person into a condition of "inside" while standing in the boundary between inside and outside, between a dimension and the other. The space of the threshold is always at the limit between two situations, between two opposite entities, is the bridge between the extremes that regulates the dialogue through a spatial experience full of dimensional variations, proportional articulation, significant variations of light and shade, definition of the permeability of the margin. It is a spatial device that stratifies the limit, the exit, the passage or the stasis.

The casbah, the primordial settlements and traditional Mediterranean contexts are the basis of the research. Their compact fabrics are micro-regulated by small spatial devices and connectors capable of becoming part of the mass and regulate transitions. Here the urban or semi-urban spaces become doorsteps, giving a opportunity to small environments to be capable of building a dense spatial dimension. The alleys, the penetration spatial structures at the urban scale, the covered passages and the interstices are gradients, areas of proximity. They define the presence of built environments and are identified as protected urban interiors, which embrace the individual and therefore are appropriate for a domestic dimension of inhabiting public space.

Very interesting for this theme are the compact fabrics of the blocks where the porosity of the masses has structured over time permeable "thicknesses" which articulate complex doorstep configurations, capable of stratifying the entrance to the family cosmos through an experience of transition, of initiation to a private and intimate interior. The constitution of shady spaces builds a "other" space in relation to the adjacent street. The proportions and the compression of the empty doorstep suggest a private nature which is separated from the public dimension of the street, although it remains linked to it. The closure of the space transforms it in a "sound detachment" place where the background street noise is heard and comes from beyond the limit.

They are the spaces where the interruption in architectural terms of the regulation of contiguous spatial relations takes place. The section is the control instrument of mediation between inside and outside. In fact, the compression which accompanies the transition and half-closes the family cosmos, without isolating it but rather articulating its dialogue balances with the urban multiplicity, is legible from the section.

The sections of the traditional city, in the mass interruptions and in the empty space of the compact solid blocks, produce proximity urban areas, alleys and interstices of extreme spatial value that embrace the urban dynamics and create possibilities for spontaneous uses due to their environmental, spatial, sensorial and emotional components.

Space components and attributes related to specific use meanings, to the appropriation and to the sensorial experience, can only come from a wise and appropriate regulation of architectural space relations. Traditional fabrics have experienced over time the density $^{8}$ of spaces and thus offer the principles of proper proportions, space measurement, spatial emotion, mediation and moderate dialogue. ${ }^{9}$

\section{Types of Doorstep Spatiality}

The meanings of the in-between spaces are

\footnotetext{
${ }^{8}$ Density generated by the material and immaterial stratification between spaces and relationships.

${ }^{9}$ Extracted from Secci, C., and Thibault, E. 2005. "Espace Intermédiaire. Formation de Cette Notion chez les Architectes." In La Société des Voisins, edited by Haumont, B., and Morel, A. pg. 23-35. “(...) During CIAM 9 another conception emerges, within the contributions made by the architects of Team 10. It is no longer simply enough to provide collective services but to prepare a complex space from the start for the daily life of the inhabitants that may be lived outside of their homes" [4].
} 
modifying themselves in narrow/medium/wide/very wide-mesh (S, M, L, XL). The historic settlement structures, the ways of inhabiting spaces, and the shapes of the living systems which are rooted in the territory in response to morphological conditions and to anthropological and geographical dynamics, are a source of knowledge of living places and provide themes and instruments to the contemporary habitat project. The exploration of some Sardinian contexts,

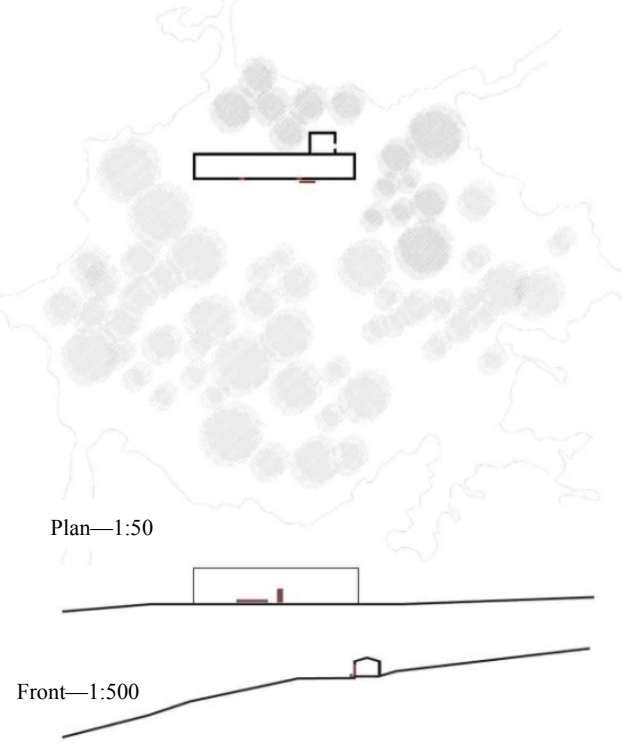

(a)

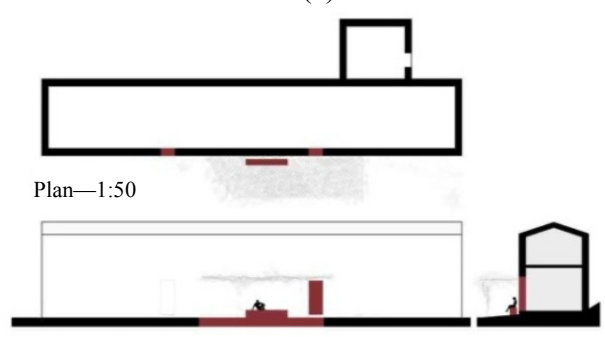

Front and section-1:50

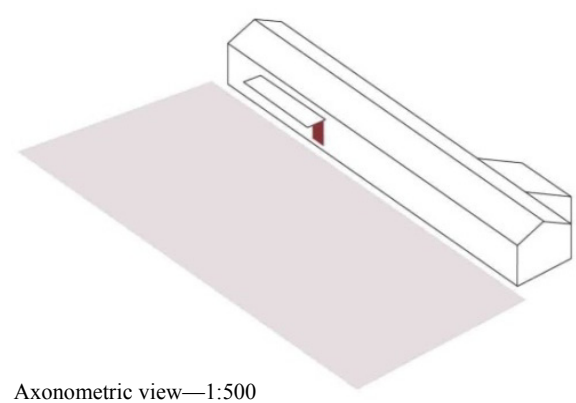

(c) including the different historical regions of Gallura, Barbagia, Campidano and Sulcis provides a comparative synthesis of the different architectural translations of doorstep relationships.

Doorstep spaces are the areas defined by shadow volumes, mass extrusions projecting indefinite pertinence spaces, entrance solutions that embrace a minimum vestibule, external stairs suitable for several uses and stasis (Figs. 1 and 2). Places for "staying" that

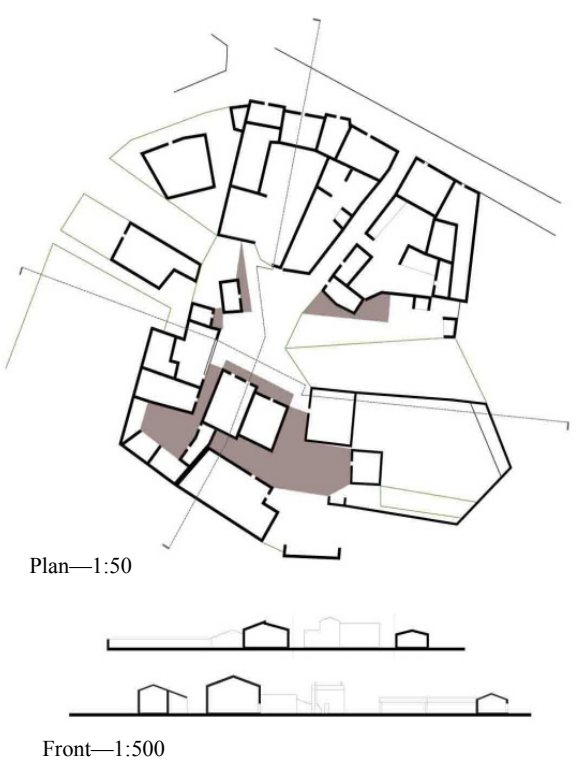

(b)
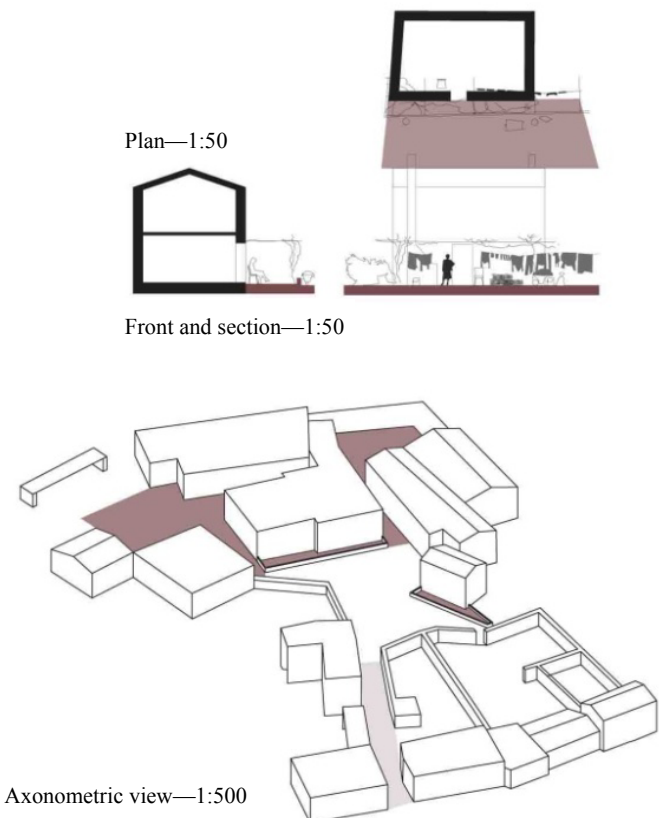

(d)

Fig. 1 Synoptic chart. Type of doorstep in the different historic settlement structures: (a) the door; (b) the rural cluster; (c) architectural scale of the door; (d) architectural scale of the rural cluster. 


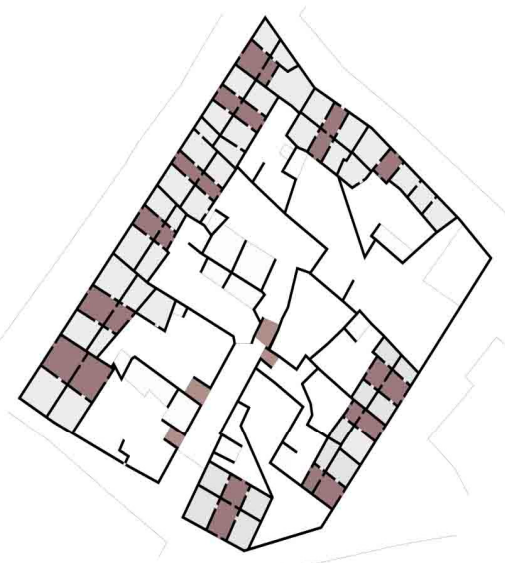

Plan-1:500

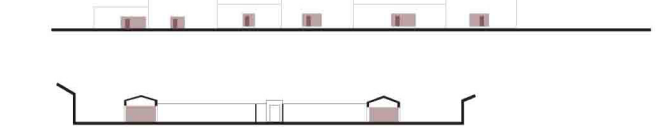

Front-1:500

(a)
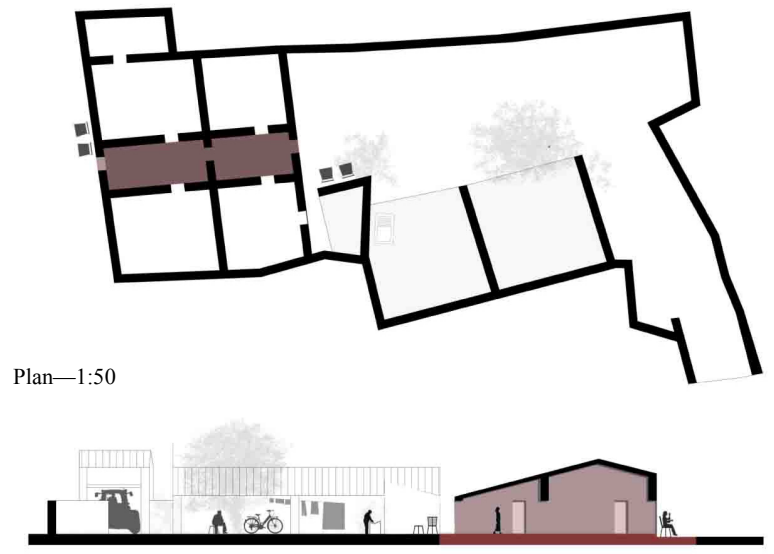

Front and section-1:50

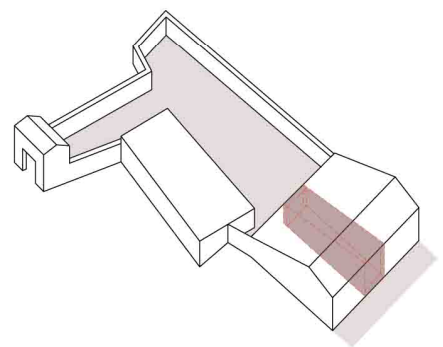

Axonometric view-1:500

(c)
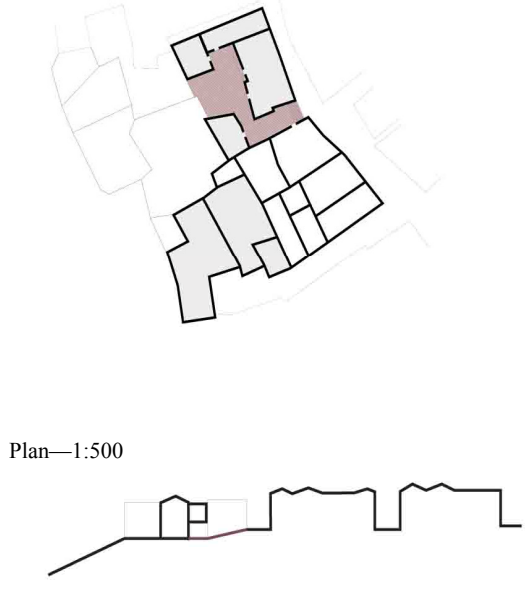

Front-1:500

(b)

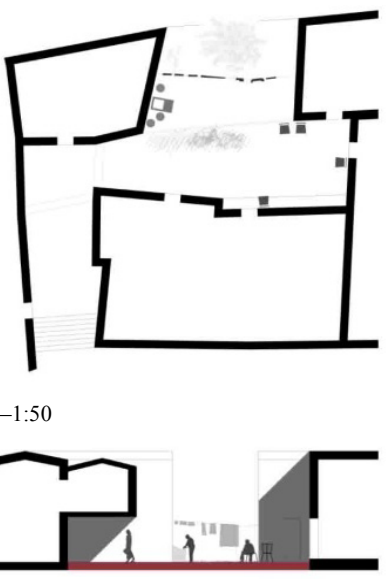

Front and section-1:50

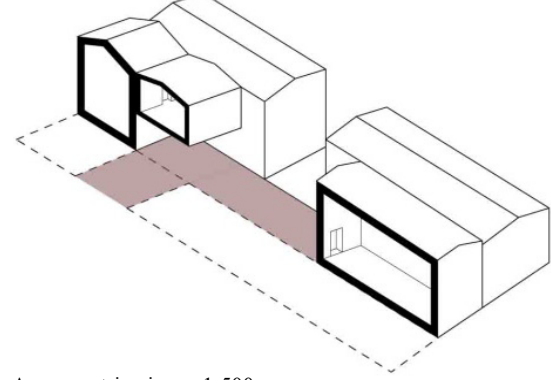

(d)

Fig. 2 Synoptic chart. Type of doorstep in the different historic settlement structures: (a) the room; (b) urban cluster; (c) architectural scale of the room; (d) architectural scale of the urban cluster. 
by virtue of their right-size, ${ }^{10}$ become areas of opportunity, complex boundaries that assimilate the multiplicity of everyday life and the cultural practices that underlie the "living", including the contemporary one, avoiding the individual simplifications.

The lesson of the historical consolidated fabrics offers itself to the contemporary project. The discovering and understanding of the structures and substructures of the habitat create opportunities and thematic richness. The appropriateness and necessity of the relational space of consolidated habitats, analyzed below, pose sense questions to the practice of the architectural project and state the meanings and layers of the places of living at different scales.

The habitat project is called to weave lines of continuity with the existing and constitute an evolving architectural fact within the process/habitat. It is possible to weave the weft of what is real, manipulate the layers of the system/habitat by implementing the fabric and reinforcing the relational weaving with thin, stratified and indeterminate patterns. The plan articulation, the section generation, and the accurate survey of the settlements "found"11 in the analyzed

\footnotetext{
${ }^{10}$ In this case the definition of the right-size is referred particularly to the suitability of the spatial solutions, to the living cultures, to the system of situations that everyday life put sin to the habitat space.

${ }^{11}$ The concept of "as found", extracted from the work that the Smithson brothers shared together with the photographer Nigel Henderson, is an important reference for the work. The grid presented at the CIAM 9, entitled "Urban Reidentification" is structured in a photographic description of "human associations", pictures of daily life. The pictures illustrate the "as found". The Smithson write: In architecture, the "as found" aesthetic was something we thought we named in the early 1950 when we first knew Nigel Henderson and saw in his photographs a perceptive recognition of the actuality around his house in Bethnal Green: children's pavement play-graphics; repetition of "kind" in doors used as site hoardings; the items in the detritus on bombed sites, such as the old boot, heaps of nails, fragments of sack or mesh and so. Setting ourselves the task of rethinking architecture in the early 1950, we meant by the "as found" not only adjacent buildings but all those marks that constitute remembrance in a place and that are to be read through finding out how the existing built fabric of the place had come to be as it was. Hence our respect for the mature trees as the existing "structuring" of a site on which the building was to be the incomer ... As soon as architecture begins to be thought about, its ideogram should be so touched by the "as
}

contexts, offer experimentation material for the study of the project and guide the re-creation of the fabric.

\section{The Door}

The dispersed settlement form of the "stazzo" (Fig. 3) (rural built unit supporting the agriculture/pastoralism work and life), typical of the contexts of the Gallura (historical region of north Sardinia), structures the relationship between inside and outside in a direct way (Fig. 1a). Only the "door" filters the dialogue with the outside, in other words with the farm.

It is in fact a habitat which is apparently structured by single points, an aggregate of a few units structuring a dual habitat form that consists of domestic space and rural space. The dwelling looks towards the extension of the grazing and cultivation space, supporting a subsistence economy, and affirms the control and protection of the land. The relationship with the outside coincides, therefore, with the administration, control and protection of land.

The relation with the outside space is simple, there are no spatial complexities which define intermediate settings. The symbiosis between the dwelling and the whole farm is in direct relation with the rural space where the dwelling finds its settlement reasons.

The introduction of the door is as follows: It is a linear limit that marks an extended relationship with landscape and divides two contiguous domestic spaces - the dwelling and "rural square" in front of it - a proximity area embraced by the articulation of the expansions of the house and of its support spaces that welcomes "staying" opportunities and working practices such as the processing of raw materials. The projection of the daily life to the outside of the house is revealed by this proximity space, an outdoor living room, extroverted by nature towards the extending of the pasture, which is comfortable, due to its specific equipment and furniture, as well as to its spatial

found" as to make it specific place. Thus the "as found" was a new seeing of the ordinary, an openness as to how prosaic "things" could re-energise our inventive activity [5]. 


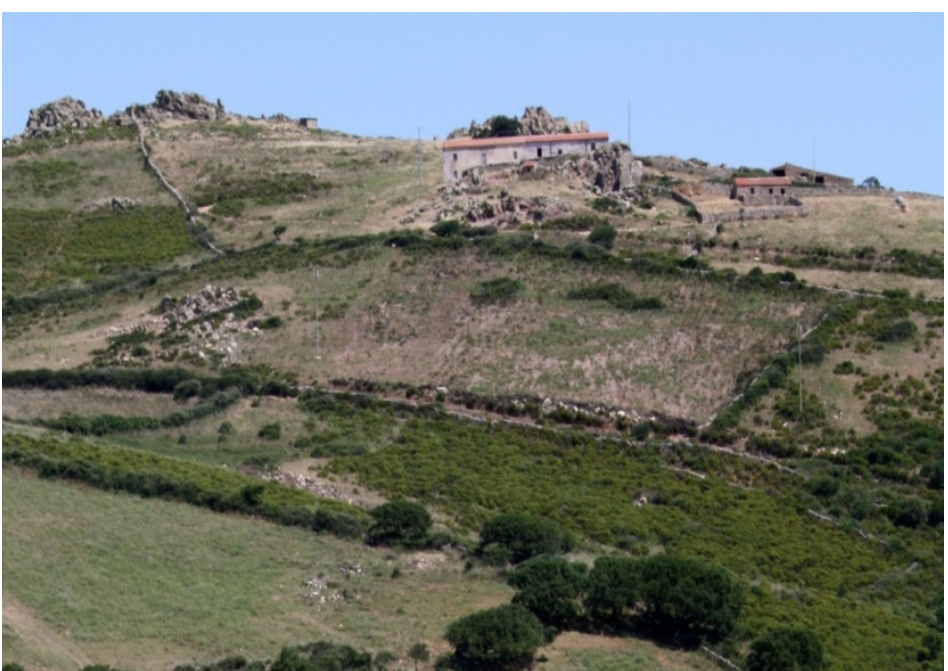

Fig. 3 The "stazzo"-Gallura, 2014.

characters. "Lu linnu", an arbour made by the weaving of vine branches, defines a shadow volume inside of which you can sit on a stone monolith.

The use of the doorstep space is a cultural phenomenon that therefore also characterizes the rural and isolated living of the "stazzo". The dialogue with the outside is, in this case, wider and in mutual relation with the dimension of the ancestral surroundings of naturalness, not concerning urban facts.

\section{Rural Clusters}

The aggregation of multiple housing units around a central common space (Fig. 1b), which depends on the territory infrastructure according to a fish-bone arrangement scheme on the main road, offers the built example of a rural cluster ${ }^{12}$ which assembles a family clan and creates a section used for production based, originally, on a subsistence economy.

The articulation of the empty space between the volumes/dwelling and the volumes/support-units reaches certain levels of complexity in clarifying the nature and vocation of spaces and different settings. The hierarchy of open spaces, diversified in "rural square", interstice, court and "pertinence" adjacent to

\footnotetext{
${ }^{12}$ They talked about "cluster" during the 10th CIAM of Dubrovnik (1956) in order to define a specific model of human association, a grouping based on a relational system. (See: Smithson, A., and Smithson, P. Urban Structuring: Studies of Alison \& Peter Smithson, London/New York 1967).
}

units, is defined each time by proportions and size of the space. Shadow volumes and different settings of the doorstep space characterize the spaces that face the entrance of the house and include "staying" opportunities embracing a space of intermediate scale between private and semi-public spheres. The "gradients" which structure the connection with the agricultural space behind living units, provide the space for controlled transits and for the work practices that are related to the post-production of the crop.

The gap-spaces between volumes create mediation interstitial settings which gather different use purposes derived from space appropriation and from the strong domestic and rural characterization. Small-scale connecting devices are suitable for regulating passages between the central common space and the metabolic agricultural areas of the single living units (Fig. 4). Spaces of mediation are capable of regulating scale relations and articulating the outside space that is treated as regimented fluid.

The affirmation of the different scales of empty spaces is at the base of the habitat of the rural cluster. The habitat "rules", the different ways of "staying" in a place, the dialogue and relations of a neighborhood system synthesised in the nucleus of the "medaus" (historical aggregation of dwelling units that gravitate around the middle common space). This settlements model is typical of the Sulcis. Those dwelling units are 


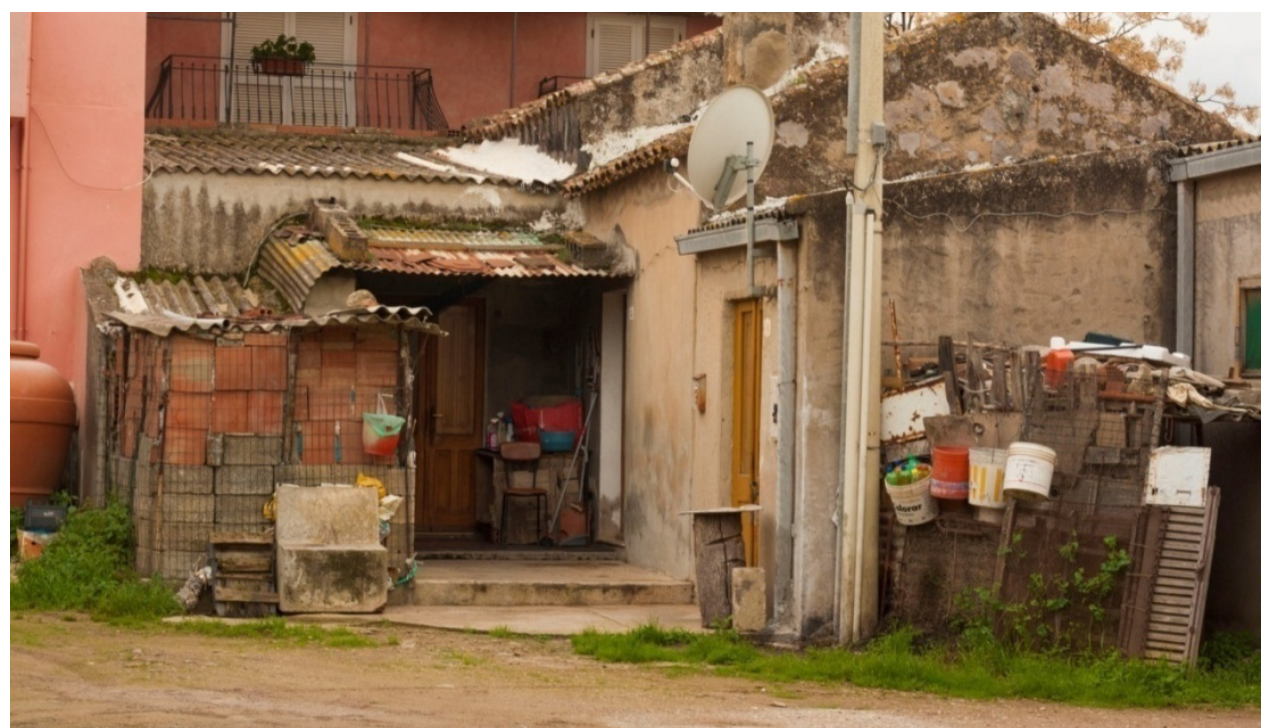

Fig. 4 The hollow space structured by the aggregation of several living units-Sulcis, Santadi, 2015.

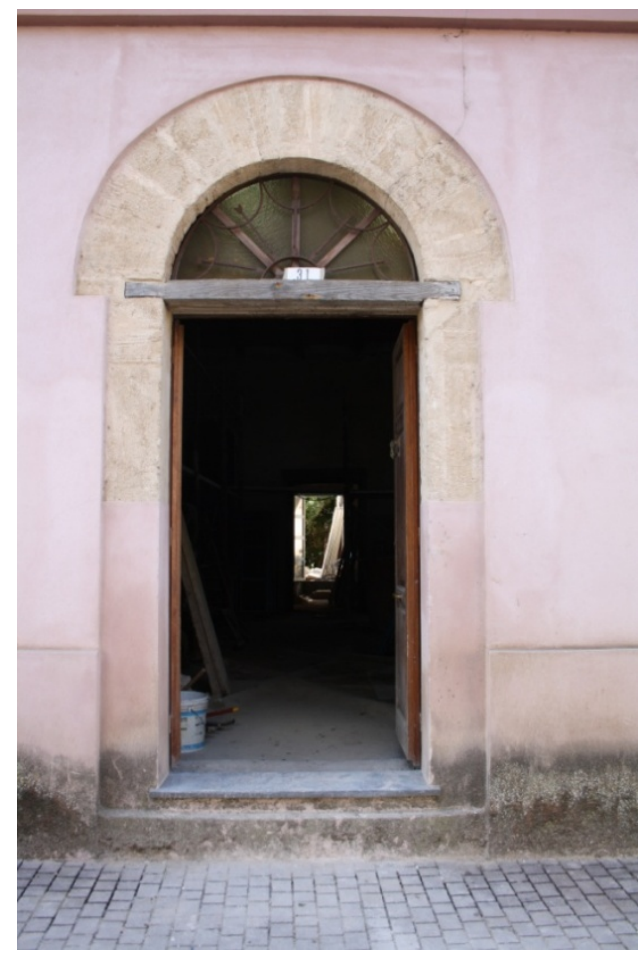

Fig. 5 The room-Campidano, Cabras, 2014.

explained and legible within the determination of characters and space vocation.

\section{The Room}

The "bark" shape of the blocks with wide-mesh of the town of Cabras (Fig. 5) (small town in central Sardinia near Oristano), constituted by the contiguity of buildings that structures the urban façade of each

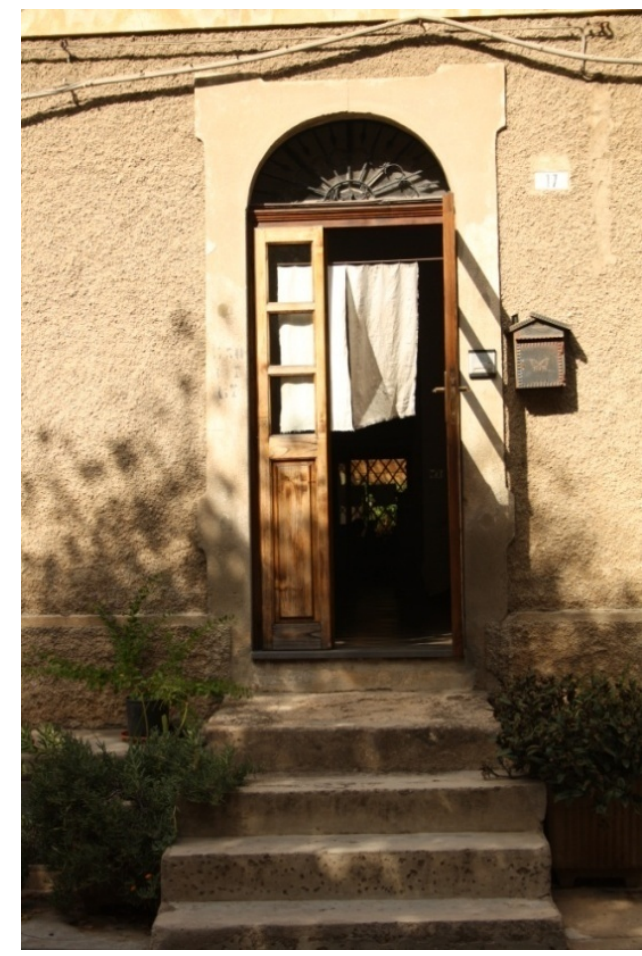

single land unit, welcomes pass-through possibilities towards the "rooms", portals and interstices between buildings.

These three devices (room, portal and interstice) govern the dialogue with the multiplicity of the urban space of the street, alley and widening spaces. In particular, the "room" absorbs the complexities of the relationships of the doorstep spaces, translates the 
extrovert component of the traditional habitat of the northwest area of the Campidano (Fig. 5) (another historical region, corresponding to the most extended plain in south-west Sardinia). The "room" introduces the typological anomaly [6] that reverses the introversion characters of the courtyard-house of the Campidano and opens a passage space between public and private, a volumetric doorstep-device that structures a possibility setting fully inside the dwelling, it is the main space of it, but focused to the dialogue with the outside space of the road and with the court (Fig. 2a).

It is the entrance room, the centripetal cell of the dwelling, the exit to the back courtyard, and the continuation and projection of the outside "living-room". It is a doorstep device extended over the entire thickness of the building which doubles, if necessary, to follow the growth process of the dwelling and to ensure always a direct connection between the outside of the road and the outside of the back court.

\section{Rur-Urban Mountain Habitats}

The fabric of the mountain urban habitat weaves connectors and relational gradients that modulate spatial relationships at the neighborhood scale by measuring and modifying the scale jumps of urban space (Fig. 2b).

The settlement forms, rooted in the soils of half of the coast line, have limited areas and a network of internal connections that develop the architectural theme of the articulation of different levels.

Long and narrow blocks structure contiguous living units with vertical development and double façades.

The basic "cell", with a clear role of structural containment of soil, includes wine cellars and storage units, while the rooms contained in the units at higher levels welcome domestic spaces with privileged entrance.

The dwelling proximity space, which includes the entrance and the support spaces, creates small areas suitable for spontaneous uses, for appropriation and personalisation. Small loggias, generated by the extrusion of the volumes above, create a shadow volume which seams perfectly suitable for a "seat" between inside and outside, between private and collective, between the dwelling and the common court (Fig. 6).

Half-closed spaces are gathered by undefined boundaries, which increase the thickness of the dwelling's perimeter. Those spaces set up the multiplicity of outside space next to the dwelling.

The mountain habitat has therefore a complex urban structure, which translates into architectural facts, at the domestic scale, the relations of closeness excluding all forms of cohabitation and modulating the dialectic layers of proximity.

The areas of the "not inside" and "nor outside", neither public nor private, neither individual nor collective translate in Aritzo small size doorstep spaces, thickened by sections with vertical development which affirm, once again, the exclusiveness of the neighborhood space, its "other" nature of urban space, its relational and plural vocation in creating comparisons between several human phenomenons, between private micro-settings, and between different living spaces.

\section{Urban Vestibules-Aritzo}

The spatial complexities of the Sardinian mountain urban fabric introduce configurations of the intermediate space extremely suitable for the modulation of the proximity relations. Abrupt direction changes and covered passages hierarchies (Fig. 7) the relationship between the dwelling and the road through the interposition of intermediate spaces that welcome transits and passages, domestic work, stasis, enjoyment of the outdoor living-room. The definition of a spatial thickness that assimilates the tensions between the domestic space and the plurality of the urban situations enriches with possibilities of the daily life outside the dwellings.

The interruption of the urban space extension can be 

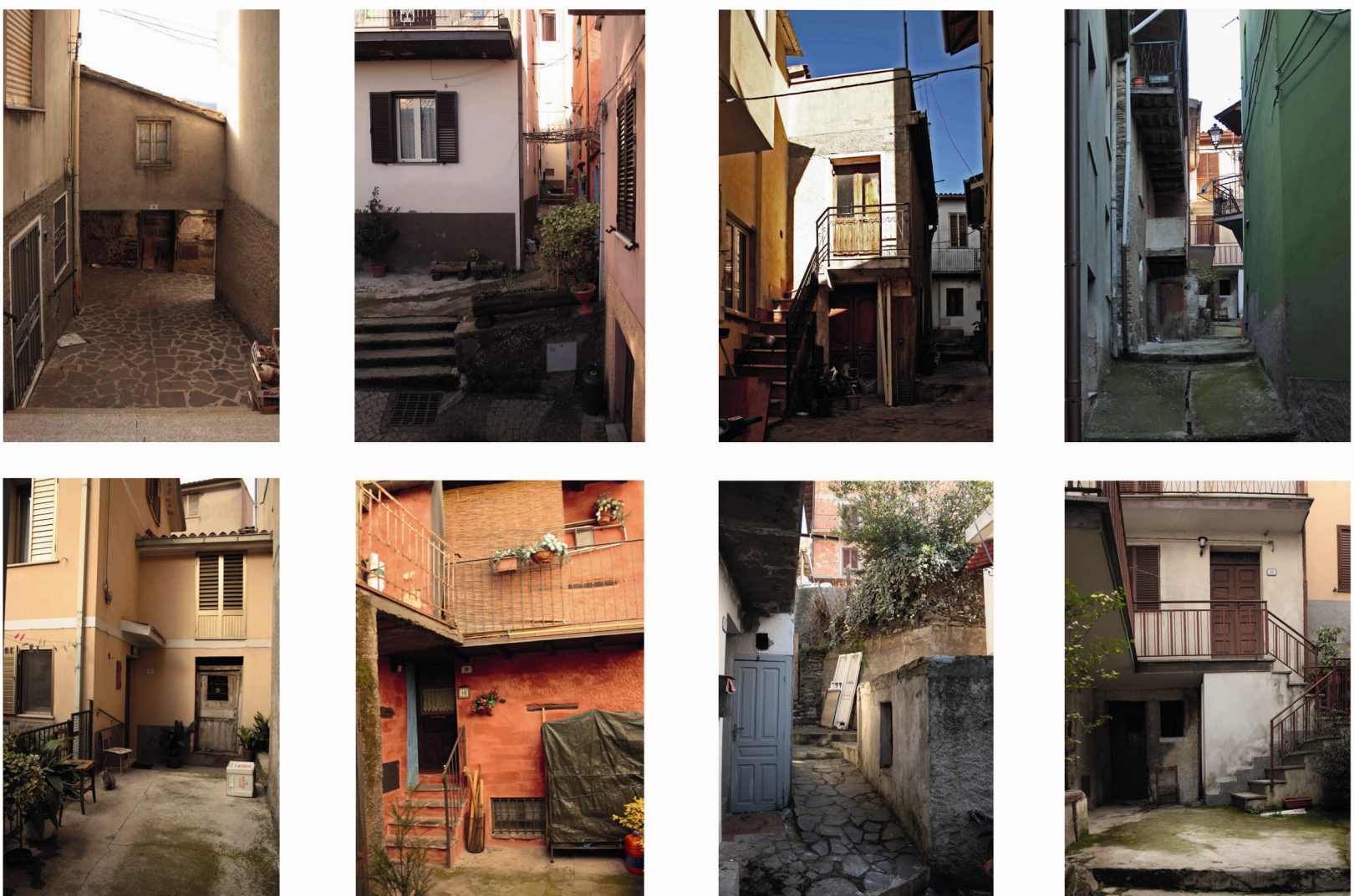

Fig. 6 The dwelling proximity space: vestibules, covered passages, a "spatial thickness" and loggias-Barbagia, Aritzo, 2014.

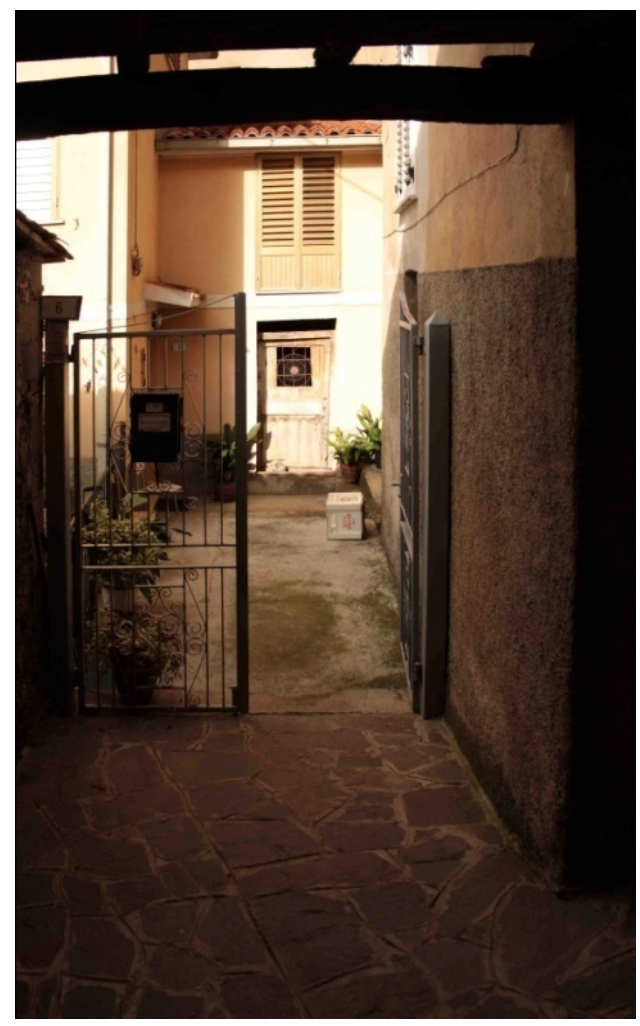

Fig. 7 One place of initiation to the private sphere-Barbagia, Aritzo, 2014. structured through the articulation of an abrupt change of direction that in the point of greater tension half-closes the space in section. A place of decompression, an area of transition, within which the space changes its nature, the urban "fluid" is compressed insinuating and adapting itself to the domestic scale (Fig. 8).

The section, which articulates the transition to an "urban inside", states the entrance moment in another place, clarifies the contact between two different space natures and welcomes its tensions.

A doorstep spatiality is, again, a intermediate space full of urban and domestic meanings capable of generating an intense spatial experience that explains space mutations.

In those case studies (Figs. 7 and 8), it is possible to read the articulation of a place of initiation to the private sphere, place of decompression, a complex architectural fact that translates the abandonment of a multiple urban condition and the introduction to a 


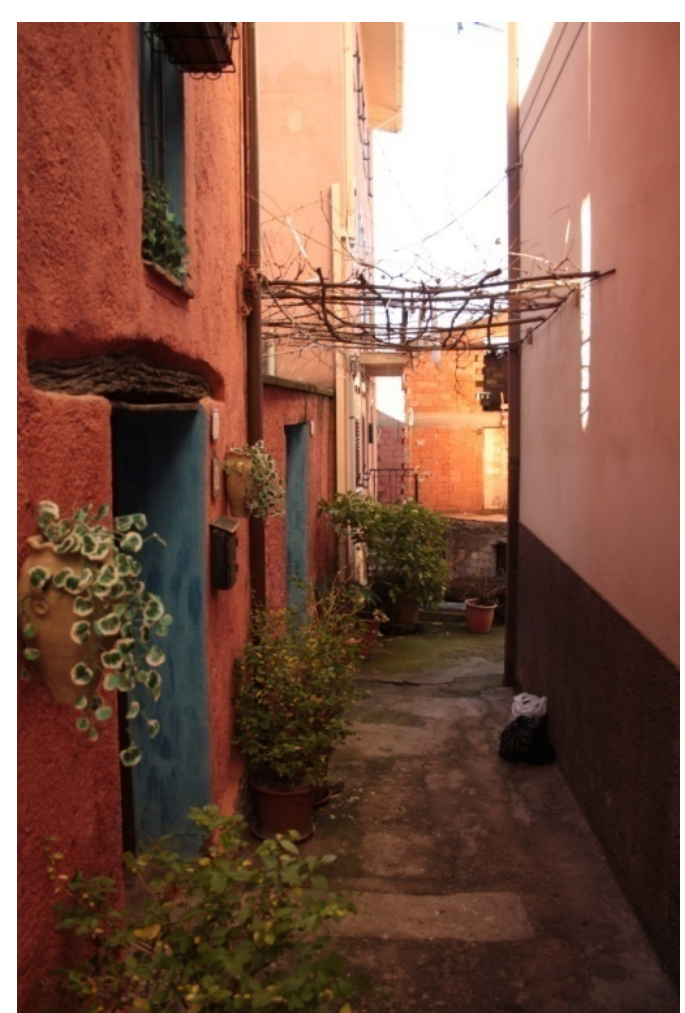

Fig. 8 Interstitial spaces-Barbagia, Aritzo, 2014.

domestic microcosm, albeit still collective.

The abrupt change of direction through the passage in an "under" space introduces to an intimate space around multiple living units which face it and project into it outside living-rooms, laundries and small spatial occasions capable of welcoming practices of domestic work. A small common court, as defined by the Recovery Manuals of Sardinia [7], a scenery of domestic purposes, whose permanent furnishings set up the "scene" of "staying" in a measured relational dimension, that offers multiple possibilities of use, is enriched by the density of architectural and domestic facts and comfortable due to its characters and environmental elements.

The dwelling, the garden and the tools, essential for the domestic metabolism, are necessary elements suitable for the life dimension which is enriched by the whole frame in which they are included.

The urban vestibules are suitable places, constantly redefined by use and intensified by new architectural and urban facts that stratify the habitat according to a

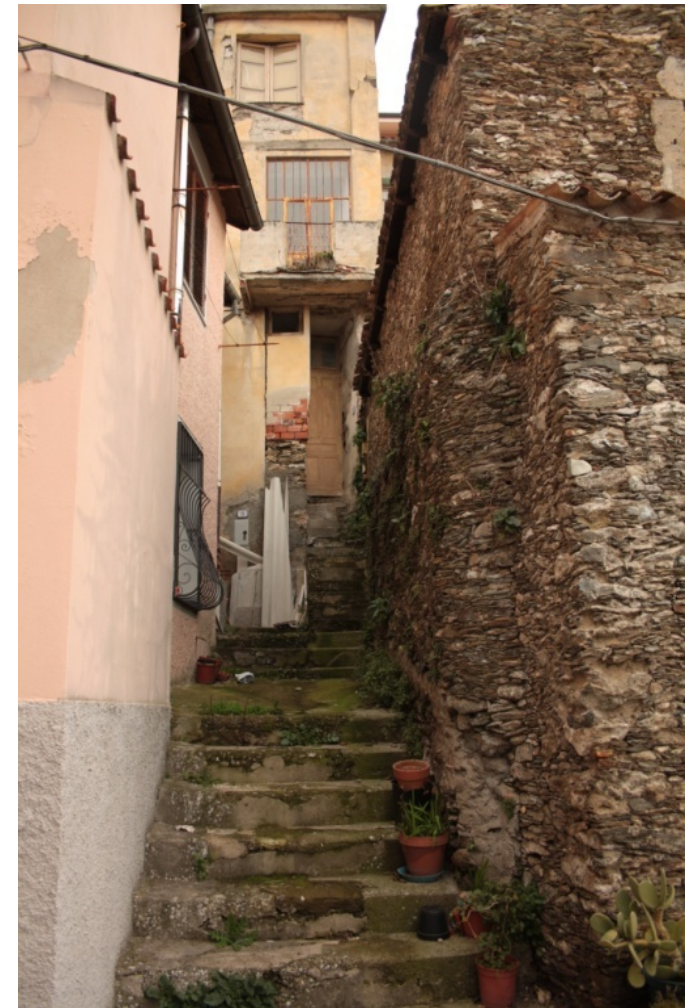

logic of processual continuity that is at the base of the settlement phenomenon.

\section{The Interstice}

The urban solid of Aritzo, strongly hierarchical in its interior, makes legible the substructure of the fine-grained spatial connectors which cut portions of compact and dense urban fabric.

Interstitial spaces that infiltrate within the built mass assimilate several living units that are projected into it (Fig. 8), and that share its margins creating comfortable and personalised spaces. Small pergolas are suspended from one side to the other of the alley, half-closing the entrance to the dwelling. The portion of the alley under the shade is suitable for other interpretations of the open outside living-room, according to the ways of living which are typical of places with temperate weather and extroverted characteristics: several human phenomenons, between private micro-settings, and between different living spaces. 


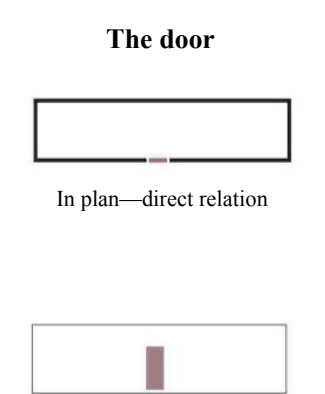

In prospect

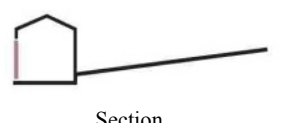

Section

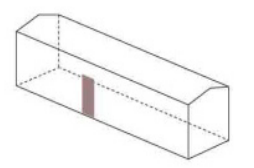

Axonometry - the threshold in solid

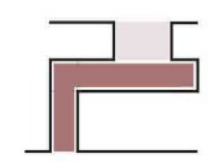

In plan—a hinge

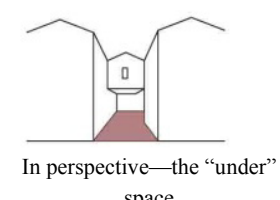
space

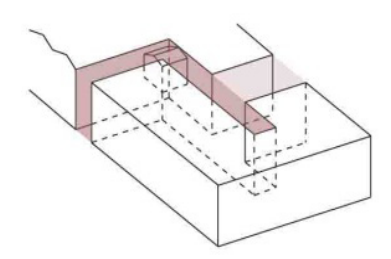

Axonometry - the interruption of the urban space extension

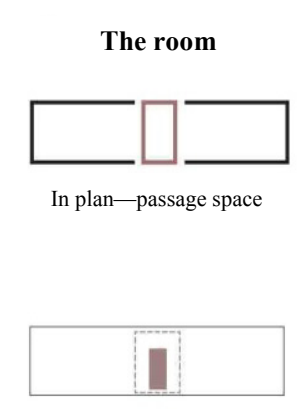

In prospect
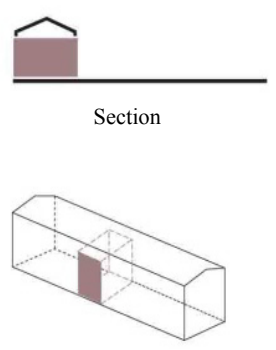

Axonometry—-the threshold that crosses the solid

(a)

The interstice

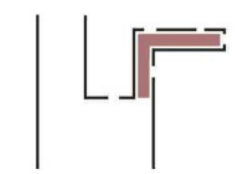

In plan - the fine-grained spatial connectors
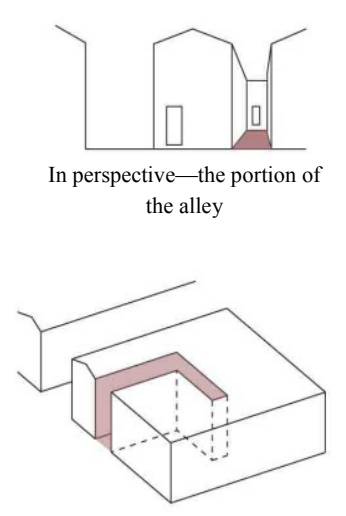

Axonometry—connectors
The loggia

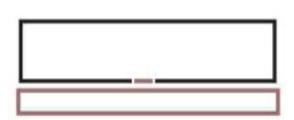

In plan-the doorstep

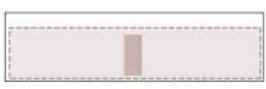

In prospect

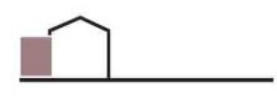

Section

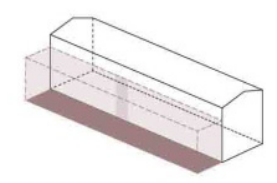

Axonometry - the threshold that digs the solid

The connectors and relational gradients

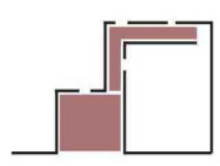

In plan-modulation of the proximity relations
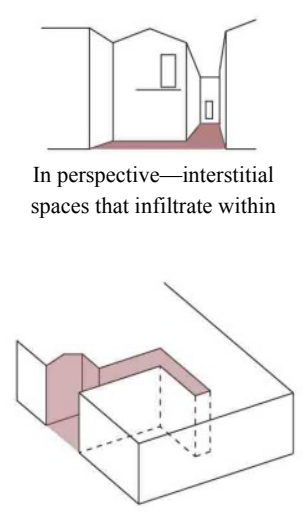

Axonometry — connectors and relational gradients
The loggia

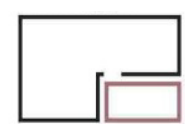

In plan-the hollow

space

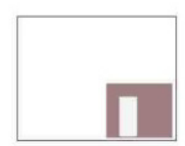

In prospect

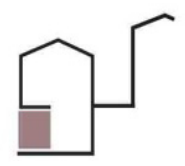

Section

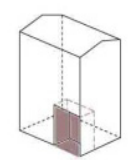

Axonometry - the threshold that digs the solid

The common court
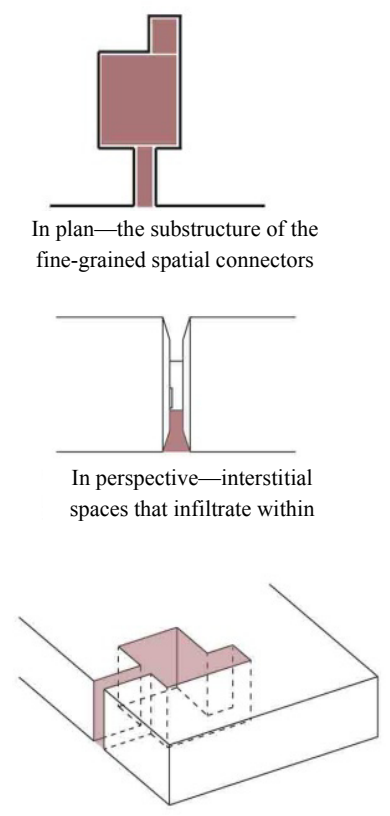

Axonometry-the hollow of the block

(b)

Fig. 9 Synoptic chart. Reading of different types of in-between space: (a) types of doorstep in Sardinia; (b) the scale jumps of urban spaces in the rur-urban mountain habitats. 


\section{Conclusions}

The critical ${ }^{13}$ reading of the living places returned by this research work can be considered as a project form, as material useful to the creative process, to the processes of generation and production of project elements. The survey conducted on the consolidated habitats, specifically the Sardinian ones, is operative project field. At the basis of this, there is the creative process, which is intended as the modification of reality, and the project intended as dialogical action with the context and the design of the urban space as relation complex between the rules that govern each space. The selection of the different case studies as examples of forms of the state of things, of the principles underlying the settlements and of the reasons that are at the basis of such forms-the representation ${ }^{14}$ of the sections and of the plan configurations, are all processes which go deep into the project feeding it and providing work materials (affirming thought and development themes) (Fig. 9). As already mentioned, the habitat contemporary project must weave continuity bounds with the existing, must translate itself in complementary terms, must interfere where the fabric porosity allows it and must create relational weaves where discontinuity appears. The reading of "reality" is something that belongs to the project, strengthening the idea that the project of the living places, i.e. the fabric of the habitat, can not be an arbitrary fact, but a necessary element deeply related to the culture and the practice of living in a specific place and time. The door, the room, the urban cluster, the vestibules and the interstices are all "methods" with which the space can be articulated and that create relations between

\footnotetext{
${ }^{13}$ The adjective "critical" refers to the conception of architecture, intended as artistic practice and as constitution of a critical distance from reality. Critical is intended within its meaning of implementation of analytical thought by means of specific tools of the subject.

${ }^{14}$ Rappresentation: explanatory description, it is due to the relation between architecture and reality, the most effective form of criticism and knowledge essential tool.
}

different-nature environments. The redrawing of the selected socio-spatial systems, in generative terms, describes project themes, constitutes meta-projects that are suitable for the definition, articulation and diversification inside several advanced project phases. The reduction in the size of "reality" and the completion of specific models lead to the abandonment of the diagram non-contextual abstraction and introduce the complexity of the real/specific space on which the project can be structured by modifying its fabric (layers).

\section{References}

[1] Montaner, M. J. 2013. Sistemas Arquitectónicos Contemporaneous. Barcelona: Editorial Gustavo Gili. (in Spanish)

[2] Mumford, E. 2002. The CIAM Discourse on Urbanism, 1928-1960. London: MIT (Massachusetts Institute of Technology) Press.

[3] Bonillo, J. L., Massu, C., and Pinson, D., eds. 2006. La Modernité Critique, Autourdu CIAM 9 d'Aix-enProvence-1953. Marseille: Editions Ibernon. (in French)

[4] Secci, C., and Thibault, E. 2005. "Espace Intermédiaire. Formation de Cette Notion chez les Architectes." In $\mathrm{La}$ Société des Voisins, edited by Haumont, B., and Morel, A. Paris: Éditions de la Maison des Sciences de l'homme, Ministère de la Culture. (in French)

[5] Smithson, A., and Smithson, P. 1990. "The "Found" and the "Found"." In The Independent Group Postwar Britain and the Aesthetics of Plenty, edited by Robbtris, D. London: MIT Press.

[6] Sanna, A., and Atzeni, C. 2008. "Architetture in Terra Cruda dei Campidani, del Cixerri e del Sarrabus." In Volume 1 della Collana I Manuali del Recupero dei Centri Storici della Sardegna. Roma: DEI Tipografia del Genio Civile. (in Italian)

[7] Sanna, A., and Cuboni, F. 2008. "Architetture in Pietra delle Barbagie, dell'Ogliastra, del Nuorese e delle Baronie." In Volume 2 della Collana I Manuali del Recupero dei Centri Storici della Sardegna. Roma: DEI Tipografia del Genio Civile. (in Italian) 